\title{
A pilot study on the prevalence of lice in Irish beef cattle and the first Irish report of deltamethrin tolerance in Bovicola bovis
}

\author{
Fiona Mckiernan ${ }^{1 *}$ DD, Jack O'Connor ${ }^{2}$, William Minchin ${ }^{2}$, Edward O'Riordan ${ }^{3}$, Alan Dillon ${ }^{4}$, Martina Harrington ${ }^{5}$ and \\ Annetta Zintl ${ }^{1}$
}

\begin{abstract}
Background: Pediculosis in cattle causes significant itching, irritation and stress to the animal, often resulting in skin damage and poor coat condition. The control of bovine pediculosis in Ireland is based predominantly on commercial insecticides belonging to one of two chemical classes, the synthetic pyrethroids and the macrocyclic lactones. In recent years, pyrethroid tolerance has been reported in a number of species of livestock lice in the United Kingdom and Australia.

Results: In this pilot survey, lice were detected in 16 (94\%) out of 17 herds visited. Two species of lice, Bovicola bovis and Linognathus vituli were identified. In vitro contact bioassays showed evidence of deltamethrin tolerance in Bovicola bovis collected from 4 farms. This was confirmed by repeatedly assessing louse infestations on treated animals on one farm.

Conclusions: To our knowledge this is the first record of insecticide tolerant populations of lice in Irish cattle. The results also provide new data on the species of lice infesting beef cattle in Ireland and the prevalence and control of louse infestations in Irish beef cattle herds.
\end{abstract}

Keywords: Lice, Pediculosis, Ectoparasiticide, Deltamethrin, Resistance

\section{Introduction}

Infestations of lice, also known as pediculosis, are more common in cattle than any other domestic animal [1]. Whilst light infestations of both sucking and biting lice often go unnoticed and are not usually considered to be of clinical importance, heavier infestations cause pruritis, which in turn leads to hair loss and skin damage often resulting in poor quality leather hides and significant economic losses to the producer [2]. Moreover, the restlessness and stress associated with pediculosis can result in decreased appetite, decreased weight gain $[3,4]$ and

\footnotetext{
* Correspondence: Fiona.mc-kiernan@ucdconnect.ie

'School of Veterinary Medicine, University College Dublin, Belfield, Dublin 4, Ireland

Full list of author information is available at the end of the article
}

decreased milk yields $[3,5]$ and should be considered an animal welfare issue. Heavy infestations with sucking lice can cause anemia $[6,7]$ which in some cases may be fatal $[8,9]$. Figure 1 shows the coat damage of an animal sampled in our study who was heavily infested with Bovicola bovis lice.

Reports on the herd prevalence of louse infestations and the cattle louse species responsible have been published from various European countries including Sweden, Iceland, Norway, England and Scotland [1014]. The only report on the prevalence of cattle lice in Ireland dates back to 1977 when Oormazdi and Baker investigated a single herd of adult cattle in a Dublinbased abattoir [15]. They recorded an infection rate of $56 \%$ and the presence of 4 different louse species. 


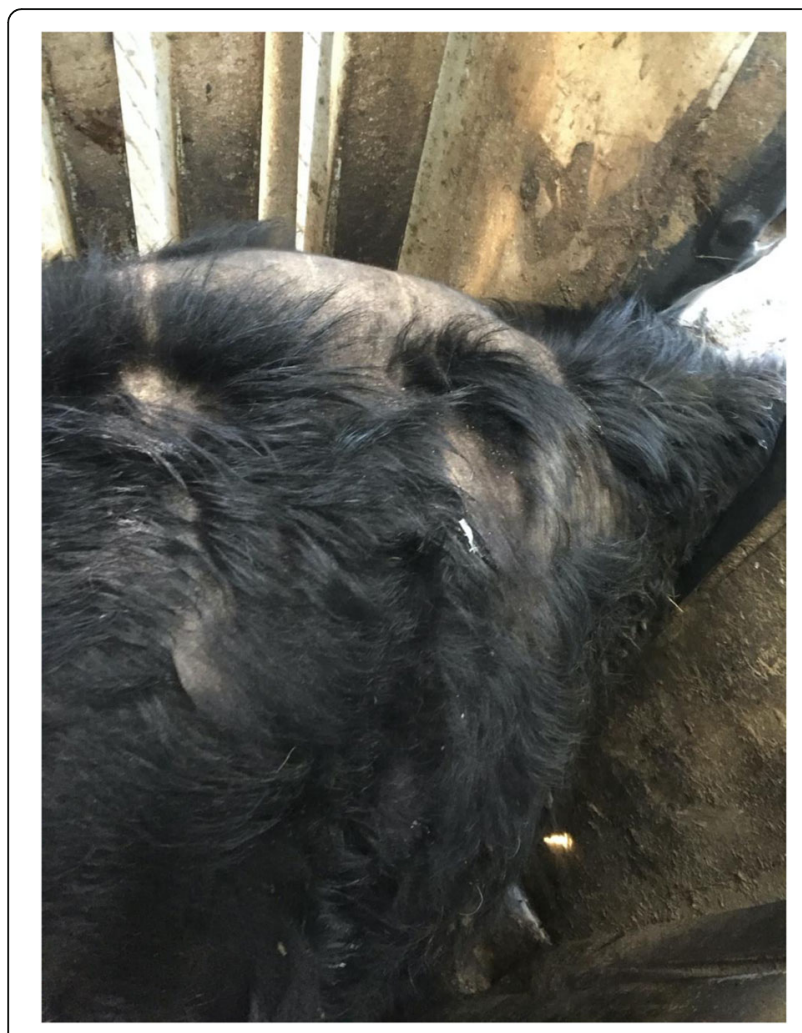

Fig. 1 A dorsal view of the shoulders of a heifer showing the coat damage caused by a heavy infestation of Bovicola bovis lice

Control of bovine pediculosis in Ireland, as in Europe, relies primarily on the use of commercial ectoparasiticides belonging to either the synthetic pyrethroid or macrocyclic lactone chemical classes. In recent years, concerns have been raised globally over the development of insecticide resistance in louse populations of livestock associated with the widespread use of ectoparasiticides in agricultural production. To date, resistance has been reported in a number of species of lice including Bovicola ovis, Bovicola ocellatus, Haematopinus tuberculatus and Haematopinus suis [16-19]. In 2015, Sands and colleagues published the first reports of deltamethrin tolerance in the cattle louse Bovicola bovis in the UK [20].

The aims of this pilot study were to evaluate the prevalence of louse infestations and species in beef cattle and to assess the efficacy of the synthetic pyrethroid deltamethrin on lice collected from heavily infested herds.

\section{Materials and methods}

\section{Farm visits, louse collection and identification}

17 beef farms were recruited opportunistically for this study with the help of Teagasc (the Irish Agriculture and Food Development Authority), MSD Animal Health and staff at the UCD School of Veterinary Medicine. None of the herds were closed. Prior to sampling it was not known if the participating farms were likely to have lice or not nor whether the participating farms had had previous problems with the efficacy of any commercial louse management products. Farms were visited between January 2019 to March 2019 and November 2019 to March 2020. At the time of the visit, cattle had been housed for between 1 and 12 weeks. The treatment history of each animal since housing of that year was recorded. Each herd was sampled once, with the exception of farm 1, which was sampled on multiple occasions as described below. The number of animals selected for sampling on each farm ranged from 20 to 65 animals (5$100 \%$ of the herd). The great variation was due to the opportunistic nature of the sampling, as visits generally coincided with a date when the farmer was putting animals through the crush for other reasons such as anthelmintic treatment. Samples were collected from 5 documented louse predilection sites: the withers, shoulder, topline, flank and the rump/tail area [21]. At each site an area twice the width of the comb (amounting to approximately $13 \mathrm{~cm}^{2}$ ) was combed 15 times using a fine-tooth plastic headlouse comb. The combings including lice, bovine skin scurf, hair and other debris were collected in a $100 \mathrm{~mm}$ diameter polystyrene petri dish. A new petri dish and clean plastic comb were used for each animal. Samples were transported to the laboratory and maintained in an unilluminated incubator at $30{ }^{\circ} \mathrm{C}$ and $75 \%$ relative humidity $(\mathrm{RH})$.

Lice were examined under a dissection microscope and identified to species, sex and lifecycle stage using the taxonomic keys provided by Lapage [21]. Adult female Bovicola bovis lice collected from 4 farms were retained for in vitro bioassays.

Repeat farm visits to assess insecticide resistance in vivo In order to assess the efficacy of ectoparasiticide treatment in vivo and to validate the results of the in vitro bioassays, 65 animals in farm 1 were sampled on four occasions over a space of 7 weeks between January 2019 and February 2019 coinciding with louse treatment dates using a louse control product of the farm manager's choice, a deltamethrin-based pour-on. Animals were treated according to the manufacturers' instruction. The same animals were sampled on each occasion. Samples were taken from each animal according to the sampling protocol described above and recorded as the number of days post-treatment for lice, beginning on 'day 0'. Combings were analyzed as described above.

\section{In vitro contact bioassay to detect insecticide resistance in the cattle chewing louse Bovicola bovis}

In vitro contact bioassays to assess the susceptibility of adult female Bovicola bovis to the synthetic pyrethroid deltamethrin were carried out as described by Levot \& Hughes [22] with some modifications. Briefly, a stock 
solution of $50 \mathrm{mg} / \mathrm{ml}$ deltamethrin was prepared by dissolving $250 \mathrm{mg}$ of $99.9 \%$ deltamethrin (Pestanal ${ }^{\circ}$ analytical standard, product no. 45,423, Sigma-Aldrich ${ }^{\circ}$, USA) in $5 \mathrm{ml}$ of $99 \%$ acetone. Stock solutions were stored at $-20{ }^{\circ} \mathrm{C}$ for up to three months. For the bioassay, dilutions of $10 \mathrm{mg} / \mathrm{ml}$ and $5 \mathrm{mg} / \mathrm{ml}$ deltamethrin were prepared from the stock solution in $99 \%$ acetone. $99 \%$ acetone was used as a negative control and $2.5 \%$ tea tree oil (Optima ${ }^{\circ}$ Australian tea tree) diluted in $99 \%$ acetone was used as a positive control [20]. $0.5 \mathrm{ml}$ of each dilution was pipetted onto $55 \mathrm{~mm}$ diameter Whatman filter paper disks, and the disks placed in $55 \mathrm{~mm}$ diameter glass petri dishes in a fume hood for $30 \mathrm{~min}$ to allow the acetone to evaporate.

Once the filter papers had dried, 10 adult female Bovicola bovis lice were placed onto each of the disks using forceps. The lids were replaced and the petri dishes returned to the incubator. Observations and records of louse mortality were made at $30 \mathrm{~min}, 1,2,3,4$ and $24 \mathrm{~h}$ from the start of the incubation period. Lice were considered dead when there was no movement of the legs, mouthpiece, antennae or abdomen even when probed with a forceps. Bioassays for each deltamethrin concentration were performed in triplicate.

As a control, the bioassay was also performed on Bovicola equi lice collected from a horse. As deltamethrinbased ectoparasiticides are not licenced for commercial use in horses in Ireland, it was assumed that these lice would be less exposed and therefore highly susceptible to exposure to deltamethrin.

\section{Structured interviews with participating farmers}

Prior to sampling, a structured interview was carried out with each farmer. In the interview, farmers were asked about the incidence of louse infestations in their herd, their use of commercial louse control products and whether they thought they were effective.

\section{Data analysis}

The results of the in vitro bioassays were expressed as percentage mean louse mortality at the various insecticide concentrations (and controls ) \pm standard error. For each bioassay, the number of lice surviving at 1 and $0.5 \%$ deltamethrin were compared to those in acetone control at the 24-hour timepoint using one-way ANOVA. Dunnett's multiple comparisons test was used for post-hoc analysis. In order to facilitate a more general comparison, the 24-hour mean louse mortalities were corrected using Abbott's formula [23].

\section{Results}

Prevalence of louse infestation

Of the 17 farms that were visited, lice were detected in 16 (94\%), with $51 \%$ (335) of 652 animals being positive for lice. The percentage of sampled animals that were positive for lice on each farm ranged from 10 to $100 \% .2$ species of lice were identified, the chewing louse Bovicola bovis and the sucking louse Linognathus vituli. $88 \%$ of infected animals were infested only with $B$. bovis and $5 \%$ only with $L$. vituli. Mixed infestations of both $B$. bovis and $L$. vituli were found in $7 \%$ of animals.

\section{Repeat farm visits to assess insecticide resistance in vivo}

On the farm where animals were sampled on four occasions to assess the efficacy of ectoparasiticide treatment in vivo, lice were present on $52 \%$ of animals in the herd on day 0 , prior to any louse treatments being administered. On day 20 post-treatment with a deltamethrinbased pour-on, $88 \%$ of animals were positive for lice and on day 27 post-treatment, $91 \%$ of animals were positive (Fig. 2). On this date (day 27), the farm manager treated all animals a second time using the same deltamethrin-based product as used previously on day 0 . On day 21 ( 21 days after the second louse treatment), lice were present on $62 \%$ of animals.

\section{In vitro contact bioassay}

In vitro contact bioassays to assess susceptibility to deltamethrin were performed on Bovicola bovis lice collected from 4 farms. These 4 farms were selected for deltamethrin susceptibility testing as large numbers of $B$. bovis lice (> 100 lice per farm) were collected during the on-site sampling visits. The 24-hour percentage mean louse mortalities (without Abbott's correction) for farms 1,2,3 and 4 are shown in Fig. 3.

On farm 1, there was a significant difference in the 24hour louse mortalities between the experimental groups ( $1 \%$ deltamethrin, $0.5 \%$ deltamethrin, acetone \& tea tree oil controls $)(\mathrm{F}=13.84, P=0.0016, \mathrm{df}=3)$. Analysis of Dunnett's multiple comparisons post-hoc test showed that there was no statistical difference between the 24hour mean louse mortalities in the $1 \%$ deltamethrin assay and the acetone control $(P=0.1667)$ however there was a significant difference between the 24-hour mean louse mortalities of the $0.5 \%$ deltamethrin and the acetone control assays $(P=0.0126)$.

On farm 2, there was a significant difference between mean louse mortalities in all of the groups $(F=5.207$, $P=0.0276, \mathrm{df}=3$ ) however post-hoc analysis showed that there was no significant difference in the mortalities of both, the 1 and $0.5 \%$ deltamethrin groups and the acetone control at $24 \mathrm{~h}(P=0.0924 ; P=0.4564)$.

On farm 3 there was also a significant difference in the mean mortalities between all experimental groups $(\mathrm{F}=$ 24.31, $P=0.0002, \mathrm{df}=3)$. The mean louse mortalities at both the $1 \%$ deltamethrin $(P=0.0003)$ and $0.5 \%$ deltamethrin $(P=0.0054)$ assays were statistically different from that of the acetone control. 


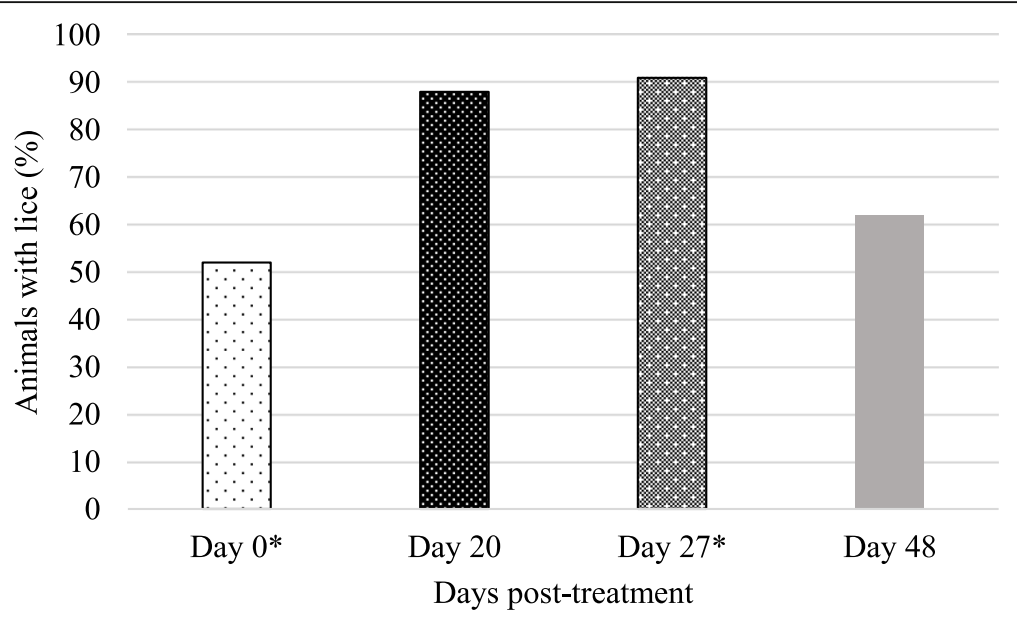

Fig. 2 The prevalence of lice pre- and post-treatment with a deltamethrin-based pour-on $(n=65)\left({ }^{*}\right.$ indicates treatment dates)

Similar results to farm 3 were observed on farm 4 . There was a significant difference in the mortalities between all of the experimental groups $(\mathrm{F}=19.00, P=$ $0.0005, \mathrm{df}=3)$ and post-hoc analysis showed that the 24hour mean louse mortalities of the $1 \%(P=0.0031)$ and $0.5 \%(P=0.0284)$ deltamethrin assays were significantly higher than the acetone control.

Exposure of Bovicola equi lice to 1 and $0.5 \%$ deltamethrin for $24 \mathrm{~h}$ resulted in $100 \%$ mortality at both concentrations of deltamethrin.

In order to facilitate a more general comparison with published figures, louse mortality rates after $24 \mathrm{~h}$ of continuous contact with filter paper impregnated with deltamethrin were corrected using Abbott's formula. At $1 \%$ deltamethrin, the percentage mean louse mortality rates following Abbott's correction were calculated as $33.34 \%( \pm 8.6 \%), 65.22 \%$ ( $\pm 8.7 \%), 95.45 \%( \pm 3.8 \%)$ and $66.67 \%( \pm 8.6 \%)$ in farms $1,2,3$ and 4 respectively. At $0.5 \%$ deltamethrin the corrected values were $61.9 \%( \pm$ $8.9 \%), 34.78 \%( \pm 8.7 \%), 59.09 \%( \pm 9 \%)$ and $44.4 \%( \pm$ $9.1 \%$ ) for farms 1, 2, 3 and 4 respectively.

\section{Structured interviews with participating farmers}

$100 \%$ of the participating farmers stated that they treat their cattle for lice each year at least once during the

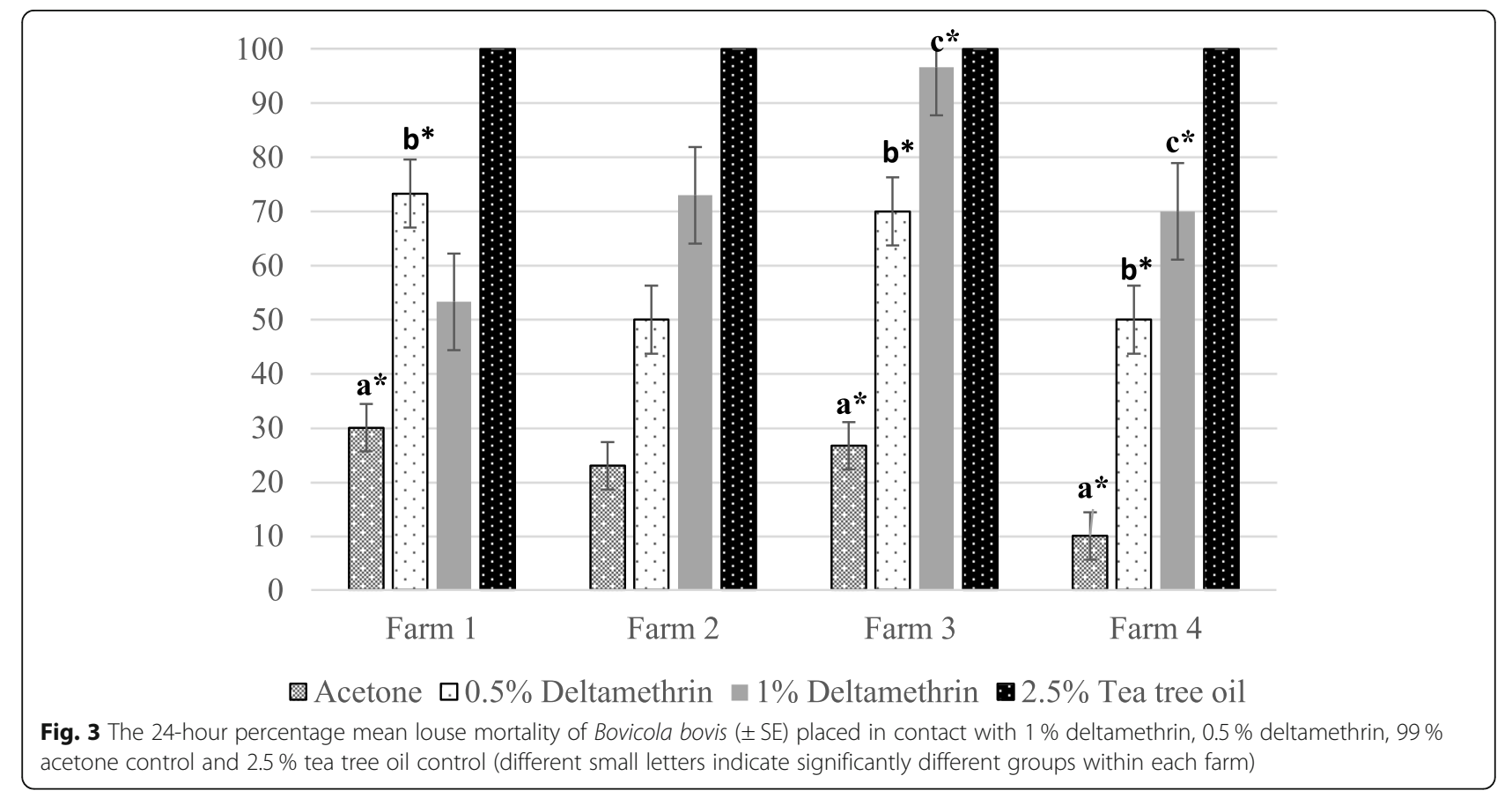


winter housing period. 14 (82\%) of the participating farmers had treated their cattle for lice in the 8 weeks prior to the sampling visit.

Two farms had used two louse management products containing different active ingredients on their cattle while the remaining 12 farms had used just one louse management product. Ivermectin-, cypermethrin- and deltamethrin-based products were most commonly used with ivermectin- and cypermethrin-based products being equal in popularity across the 14 farms (31.25\%) followed by deltamethrin-based products (25\%). Doramectin-based products were used on just 1 farm (6.3\%). One farmer used a diazinon-based sheep dip product as he found products licensed for use in cattle to be ineffective.

13 (76\%) farmers reported no problems with louse infestations within their herd or with the efficacy of commercial louse management products. However, 4 farmers stated they had experienced efficacy issues with various deltamethrin-based products requiring several treatments to be effective.

\section{Discussion}

In this pilot study, lice were recorded on $94 \%$ of farms and on $51 \%$ of animals confirming anecdotal evidence that seasonal infestations of cattle herds with lice are very common in Ireland. This herd prevalence was similar to what has been reported in the UK (75-80\%) [13, 14], Sweden (93\%) [10] and Iceland (70\%) [11]. Two species of lice were identified in the present study, the chewing louse Bovicola bovis and the sucking louse Linognathus vituli. Similar to reports from the UK [13, 14, 24], B. bovis was by far, the more prevalent. In contrast, a previous study conducted by Oormazdi and Baker, identified four species of lice in a group of cattle in a Dublin-based abattoir; the chewing louse Bovicola bovis and the sucking lice Solenopotes capillatus, Haematopinus eurysternus and Linognathus vituli [15]. Previous studies in the UK and Iceland also reported $S$. capillatus from cattle herds [11, 14]. According to Craufurd-Benson, the prevalence of $S$. capillatus in cattle herds is commonly underreported due its small size [25]. Furthermore, the face and head of the animal, which has been identified as a common predilection site of S. capillatus [24, 25], was not examined in this pilot study for logistical and animal welfare reasons. Further work will be required to determine whether this louse species was overlooked in our study or whether it has become less prevalent.

Results of the structured interviews showed that farmers rely on a range of commercial ectoparasiticides including both synthetic pyrethroid, particularly deltamethrin-, and macrocyclic lactone-based products. However, a number of farmers indicated efficacy problems with the former. These observations were born out by the in vitro contact bioassays using deltamethrin which showed deltamethrin-tolerance in B. bovis lice collected from four farms.

It is important to point out that published information on the minimum concentration of synthetic pyrethroids required to kill lice in livestock is somewhat conflicting. With regard to in vitro contact bioassays to assess insecticide tolerance in lice, FAO guidelines state that the survival of one or more louse at $5 \mathrm{mg} / \mathrm{l}(0.0005 \%)$ or greater is taken as an indication of resistance'[26]. In contrast Boray and colleagues reported the minimum synthetic pyrethroid concentration required to kill $B$. ovis lice to be $0.5 \mathrm{ppm}$ or $0.00005 \%$, an order of a magnitude lower than that reported by the FAO [27]. In our study, $B$. bovis lice from 3 farms tolerated exposure to $1 \%$ deltamethrin and B. bovis lice from all 4 farms tolerated exposure to $0.5 \%$ deltamethrin, both of which are significantly greater concentrations than those specified by the FAO or Boray and colleagues. Using a commercial $1 \%$ deltamethrin pour-on product to assess B. bovis tolerance in vitro, Sands and colleagues reported high levels of louse mortality in response to the undiluted product [20]. However, the authors attributed the high mortality rate to the suffocation of the lice by the caprylic triglyceride excipient rather than the susceptibility of the lice to deltamethrin. As we used laboratory-grade deltamethrin without oily excipients the louse mortality rates we observed were unequivocally due to the drug.

Because the dispersal of the insecticide through the coat of the treated animal is non-uniform [17, 28, 29], it has been suggested that the concentrations of deltamethrin that $B$. bovis are exposed to in in vitro bioassays are probably considerably higher than the concentrations that the lice are exposed to in vivo [20] and that in vitro testing is more reliable than in vivo testing [17]. We found that observations during repeat visits of one farm (farm 1) before and after treatment with a deltamethrinbased pour-on correlated well with the bioassay results.

B. equi lice proved to be an excellent control for the bioassay as they were found to be fully susceptible to deltamethrin. Similar results were reported in a French in vivo study in a group of horses infested with $B$. equi [30]. There are currently no commercial deltamethrinbased louse management products licensed for use in horses in Ireland [31] which probably accounts for the high susceptibility of $B$. equi lice to this ectoparasiticide.

Chewing lice are probably more prone to developing resistance than sucking lice because they are less affected by systemic treatments. Insecticides that are applied to the animal's coat disperse non-uniformly, probably resulting in the exposure of lice to sub-lethal concentrations and facilitating the emergence of pyrethroidtolerant louse populations [17]. Moreover, the ability of 
Bovicola species to reproduce by parthenogenesis is also considered to be a major contributor to the emergence of insecticide resistance in Bovicola lice [17].

The widespread (over)use of pyrethroid-based products has led to the emergence of deltamethrin-resistant $B$. bovis lice in the UK [20], cypermethrin, alphacypermethrin and deltamethrin- resistant $B$. ovis lice in Australia [16, 32, 33] and cypermethrin and permethrin resistant $B$. ocellatus lice in the UK [17].

In comparison to the risks and the management of resistant populations of endoparasites such as parasitic nematodes and flukes, pesticide resistance in ectoparasites has not been given the same level of attention. Current methods for insecticide susceptibility testing are also less practical and limited in comparison to endoparasites, where laboratory tests such as the faecal egg count reduction tests are easily accessible, providing farmers with accurate information on the occurrence of endoparasite resistance on their farm. Moreover, providing advice on how to avoid resistance development within these populations remains a significant challenge, particularly with regard to obligate parasites such as lice. Firstly, when implementing integrated pest management strategies, the official advice is to use non-chemical treatment alternatives where possible [26]. However, there are very few non-chemical alternatives available to manage infestations of lice in comparison to other ectoparasites such as ticks, who can be targeted within the environment by means of pasture and grazing management. Secondly, current advice on how to manage resistant louse populations is quite conflicting and confusing. For example, official guidelines state that in order to reduce the incidence of insecticide resistance within louse populations, farmers should avoid an annual 'blanket treatment' of the entire herd in order to avoid unnecessarily treating un-infested animals [26]. However, in the same document it is also noted that by only treating the animals that are presenting with clinical signs of lice infestation, an effective reduction of overall louse populations within the herd is unlikely, as lice from untreated animals will spread to treated animals, re-establishing the infestation and necessitating subsequent treatments. Moreover, rotation between chemical classes as recommended to avoid resistance development is difficult due to the limited number of chemical classes that are licensed to treat cattle lice both in Ireland and abroad. Therefore, implementing this strategy is difficult and its effectiveness is limited, particularly when resistance to one chemical class has already occurred.

It is clear that in order to reduce the reliance of farmers on chemical treatments for treating infestations of lice, non-chemical alternatives should be made readily available. Future studies are warranted in order to evaluate the viability and functionality of non-chemical treatments such as essential oils for treating infestations of lice in cattle. Moreover, straight-forward and easy-tofollow advice on sustainable control measures for lice and avoidance of insecticide tolerance needs to be developed. Routine ectoparasiticide susceptibility testing, similar to what is available for endoparasites of livestock should also be made readily accessible to farmers. This will not only allow for a better understand of the levels of ectoparasite insecticide resistance occurring on the farm but could also serve to improve productivity and animal welfare.

In order to slow the emergence of insecticide-resistant populations of lice amongst cattle herds, the management of cattle during the winter housing period should be considered holistically. According to official guidelines, overcrowding of animals within sheds should be avoided where possible during the winter housing period, as the crowding of animals within sheds can play a role in the increase in louse numbers during this period [26]. Whilst we recognize that this may not be a feasible louse control strategy for some producers, we feel that it is important to note that avoiding overcrowding during the winter housing period is one of the few nonchemical louse control strategies currently available. Anecdotal evidence collected from the participants in our study suggested that the use of hair clipping along the topline of the animal may also serve as a non-chemical method of louse control however at present there is no scientific evidence available to confirm these findings.

It is recommended that all newly purchased stock are quarantined and treated for lice upon arrival to the farm. When treating animals for lice, care should be taken to ensure that dosing is carried out correctly by following the manufacturers' guidelines. With regards to the use of Macrocyclic Lactone-based products, the product user should ensure that each animal is treated according to their weight and should regularly check that the dosing device is calibrated correctly to prevent underdosing [26].

It is important to note that the results of the study are somewhat biased due to the opportunistic sampling method, the relatively small sample size and the deviations in the number of animals sampled on each participating farm. Therefore, future studies including a larger, more representative number of farms are warranted in order to gain a better understanding of the prevalence of lice species and infestations in cattle (including dairy) and the levels of ectoparasiticide tolerance in Irish cattle lice. Despite this, this study presents new data on the emergence of insecticide-resistance populations of lice and to our knowledge, the first record of deltamethrin resistance in $B$. bovis lice in Irish cattle.

\section{Conclusions}

The occurrence of pediculosis in cattle herds is associated with significant production losses and animal 
welfare concerns. With the emergence of insecticidetolerant populations of lice, information on the prevalence and control of louse infestations is important in order to ensure that infestations can be appropriately controlled and the spread of insecticide resistance slowed.

Our study provides new information on the cattle louse species present in Ireland and the control measures used by Irish farmers. Furthermore, we provide evidence that pyrethroid-tolerant populations of B. bovis lice are also emerging in Ireland, adding to existing reports of insecticide tolerance occurring globally in livestock lice.

\section{Abbreviation}

FAO: The Food and Agriculture Organization of the United Nations

\section{Acknowledgements}

The authors gratefully acknowledge MSD Animal Health for funding this study. We would also like to thank Eddie Mulligan and Francis Collier (Teagasc Grange) for their helpful insights and all of the participating farmers and farm managers for facilitating the sampling visits.

\section{Authors' contributions}

FM carried out the field and lab work and drafted the manuscript. JO'C, WM and $A Z$ conceived and planned the study. JO'C, WM, EOR, AD and MH helped to organize logistics and to recruit farmers. AZ helped in selecting and optimizing the various methods used in the study and in drafting the manuscript. The author(s) read and approved the final manuscript.

\section{Funding}

This study was completed as part of the project The prevalence and control of ectoparasites in Irish cattle herds' funded by MSD Animal Health.

\section{Availability of data and materials}

Not applicable.

\section{Declarations}

\section{Ethics approval and consent to participate}

Not applicable.

\section{Consent for publication}

Not applicable.

\section{Competing interests}

The authors declare that JO'C and WM are employees of MSD Animal Health and helped to secure the funding for this study.

\section{Author details}

'School of Veterinary Medicine, University College Dublin, Belfield, Dublin 4 Ireland. ${ }^{2}$ MSD Animal Health, Dublin, Ireland. ${ }^{3}$ Teagasc, Animal \& Grassland Research and Innovation Centre, Grange, Dunsany, Co. Meath, Ireland. ${ }^{4}$ Teagasc Moorepark, Fermoy, Co. Cork, Ireland. ${ }^{5}$ Teagasc Oakpark, Co. Carlow, Ireland.

\section{Received: 8 January 2021 Accepted: 21 June 2021}

Published online: 05 July 2021

\section{References}

1. Urquhart GM, Armour J, Duncan JL, Dunn AM, Jennings FW. Veterinary Parasitology. Essex: Longman Scientific and Technical; 1987.

2. Coles GC, Hadley PJ, Milnes AS, Green LE, Stosic PJ, Garnsworthy PC Relationship between lice infestation and leather damage in cattle. Veterinary Record. 2003;153:255-9.

3. Matthysse JG. Cattle Lice, Their Biology and Control. Cornell Univ Agricul Exper Station. 1946;832:1-67.
4. Gibney VJ, Campbell JB, Boxler DJ, Clanton DC, Deutscher GH. Effects of Various Infestation Levels of Cattle Lice (Mallophaga: Trichodectidae and Anoplura: Haematopinidae) on Feed Efficiency and Weight Gains of Beef Heifers. J Econ Entomol. 1985;78:1304-7.

5. Fadok VA. Parasitic skin diseases of large animals. Veterinary Clinics of North America. 1984;6:3-22.

6. Ammelounx B. Severe anaemia in a calf as a result of heavy louse infestation (Linognathus vituli). Tierdrztliche Umschau. 1980:35:692-6.

7. Mehrotra P, Singh T. Studies on some blood constituents of calves infested with Linognathus vituli (Linn). Indian J Anim Health. 1986;25:29-32.

8. Lasisi OT, Eyarefe OD, Adejinmi JO. Anaemia and Mortality in Calves Caused by the Short-Nosed Sucking Louse (Haematopinus Eurysternus) (Nitzsch) in Ibadan. Nigerian Vet J. 2010;31:295-9.

9. Otter A, Twomey DF, Crawshaw TR, Bates P. Anaemia and mortality in calves infested with the long-nosed sucking louse (Linognathus vituli). Veterinary Record. 2003;153:176-9.

10. Christensson D, Gyllensvaan C, Skiøldebrand E, Viring S. Løss på nøtkreatur i Sverige -en inventering (Lice in Swedish cattle -a survey). Svensk veterinártidskrift. 1994:46:119-21.

11. Eydal M, Richter S. Lice and mite infestations of cattle in Iceland. Icelandic Agricultural Sci. 2010;23:87-95.

12. Nafstad O, Grønstøl H. Eradication of Lice in Cattle. Acta Vet Scand. 2001;42: 81-9.

13. Milnes AS, Green LE. Prevalence of lice on dairy cattle in England and the bordering counties of Wales. Vet Rec. 1999;145:357-62.

14. Titchener RN. Prevalence of cattle lice on calves. Vet Record. 1983;112:460.

15. Oormazdi H, Baker KP. The effects of warble fly dressing using an organophosphorus compound on bovine pediculosis. Vet Parasitol. 1977;3: 85-8.

16. Levot G, Johnson PW, Hughes PB, Powis KJ, Boray JC, Dawson KL. Pyrethroid resistance in Australian field populations of the sheep body louse. Bovicola (Damalina) ovis Medical Veterinary Entomology. 1995:9:59-65.

17. Ellse L, Burden F, Wall R. Pyrethroid tolerance in the chewing louse Bovicola (Werneckiella) ocellatus. Vet Parasitol. 2012;188:134-9.

18. Singh NK, Haque M, Singh J, Singh H. Detection of deltamethrin resistance in buffalo louse Haematopinus Tuberculatus. Buffalo Bulletin. 2015;34:209-14.

19. Müller A, Bülow T. The resistance of the pig louse Haematopinus suis L. to insecticides used in the GDR. Monatshefte für Veterinärmedizin. 1988:43:230-2.

20. Sands B, Ellse L, Mitchell S, Sargison ND, Wall R. First report of deltamethrin tolerance in the cattle chewing louse Bovicola bovis in the UK. Vet Rec. 2015;176:231.

21. Lapage G, Gibson TE, Beesley WN. Veterinary parasitology. 2nd ed. Edinburgh: Oliver \& Boyd; 1968

22. Levot GW, Hughes PB. Laboratory studies on resistance to cypermethrin in Damalina ovis (Shrank) (Phthiraptera: Trichodectidae). Aust J Entomol. 1990; 29:257-9.

23. Abbott WS. A Method of Computing the Effectiveness of an Insecticide. J Econ Entomol. 1925;18:265-7.

24. Milnes AS, O'Callaghan CJ, Green LE. A longitudinal study of a natural lice infestation in growing cattle over two winter periods. Vet Parasitol. 2003; 116:67-83.

25. Craufurd-Benson HJ. The cattle lice of Great Britain. Parts I and II. Parasitology. 1941:33:331-58.

26. FAO. Guidelines resistance management and integrated parasite control in ruminants. 2004

27. Boray J, Levot GW, Plant JW, Hughes PB, Johnson PW. Resistance of the sheep body louse Damalina ovis to the synthetic pyrethroids. In Australian Advances in Veterinary Sciences (Edited by P.M Outerridge). Australian Veterinary Association, NSW. 1988;130-136.

28. Kettle PR, Watson AJ, White DA. Evaluation of a deltamethrin formulation as a back-line treatment of sheep for the control of the sheep body louse (Damalinia ovis). New Zealand J Exper Agriculture. 1983;11:321-4.

29. Johnson PW, Darwish A, Dixon R, Steel JW. Kinetic Disposition of Xylenebased or Aqueous Formulations of Deltamethrin Applied to the Dorsal Midline of Sheep and Their Effect on Lice. Int J Parasitol. 1995;25:471-82.

30. Castilla-Castaño E, Vischi A, Navarro C, Lecru LA, Ribeiro C, Pradier S, Cadiergues M. Control of lice infestation in horses using a $10 \mathrm{mg} / \mathrm{mL}$ deltamethrin topical application. Irish Vet J. 2017:70:1-5.

31. HPRA. 2020. Available at http://www.hpra.ie/homepage/veterinary/veterina ry-medicines-information/find-a-medicine?query=Deltamethrin\&field= ACTIVESUBSTANCES Accessed 9th July 2020. 
32. James PJ, Saunders PE, Cockrum KS, Munro KJ. Resistance to synthetic pyrethroids in South Australian populations of sheep lice (Bovicola ovis) Aust Vet J. 1993;70:105-8.

33. Levot $\mathrm{G}$. Resistance and the control of lice on humans and production animals. Int J Parasitol. 2000;30:291-7.

\section{Publisher's Note}

Springer Nature remains neutral with regard to jurisdictional claims in published maps and institutional affiliations.

Ready to submit your research? Choose BMC and benefit from:

- fast, convenient online submission

- thorough peer review by experienced researchers in your field

- rapid publication on acceptance

- support for research data, including large and complex data types

- gold Open Access which fosters wider collaboration and increased citations

- maximum visibility for your research: over $100 \mathrm{M}$ website views per year

At BMC, research is always in progress.

Learn more biomedcentral.com/submissions 